\title{
Velocardiofacial (Shprintzen) syndrome: an important syndrome for the dysmorphologist to recognise
}

\author{
A H Lipson, D Yuille, M Angel, P G Thompson, J G Vandervoord, E J Beckenham
}

\begin{abstract}
We report the dysmorphological, genetic, and speech therapy aspects of 38 cases of velocardiofacial syndrome presenting to, a craniofacial clinic and a specialised children's hospital, to indicate a relatively low incidence of clefting, good response to pharyngoplasty, considerable variability of the syndrome, and two further familial cases. We emphasise the low index of suspicion by paediatricians and paediatric subspecialists which resulted in delayed diagnosis and delayed treatment for the hypernasal speech and velopharyngeal insufficiency for periods of four months to seven years.
\end{abstract}

Velocardiofacial syndrome (VCFS) was first delineated in 12 children by Shprintzen et al, ${ }^{1}$ though Strong ${ }^{2}$ had described a familial case previously. The features of the syndrome include overt and submucous clefting of the palate, cardiac anomalies, particularly of the conotruncal type, hypotonia, myopathic and dysmorphic facies, developmental delay and learning difficulties, small stature, velopharyngeal insufficiency, and a variety of other

The Cleft Palate Clinic, Genetics and Dysmorphology Unit, The Children's Hospital, PO Box 34, Camperdown, Sydney, NSW 2050, Australia.

A H Lipson

Department of Speech Pathology, The Children's Hospital, Sydney, Australia.

$D$ Yuille, $M$ Angel

Department of Plastic Surgery, The Children's Hospital, Sydney, Australia.

P G Thompson, J G Vandervoord

Department of Otolaryngology, The Children's Hospital, Sydney, Australia.

E J Beckenham

Correspondence to Dr Lipson.

Received for publication 8 January 1991.

Accepted for publication 5 February 1991. anomalies. ${ }^{13}$ Patients may manifest overt or subclinical features of the Di George anomaly. ${ }^{245}$ Although familial cases have been described indicating dominant inheritance, ${ }^{3467}$ a consistent aetiology is not apparent, indicating that the condition may be heterogeneous in aetiology. The great majority of patients have been described from one centre ${ }^{13-57-12}$ where it has been reported to be the most common cause of clefting. ${ }^{8}$

\section{Patients}

Of our 38 patients, 19 were male and 19 female. A representative sample of facial features is shown in figs 1 to 8 . The average age of referral was 6 years

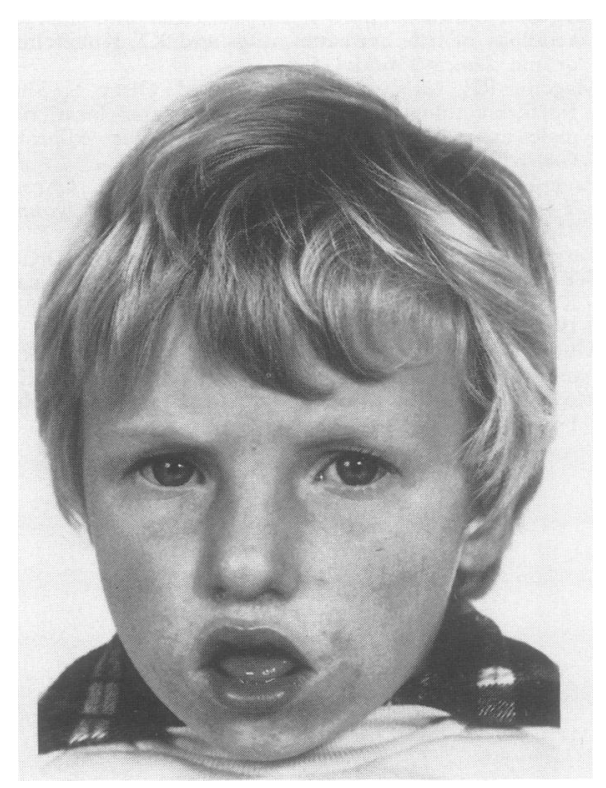

Figure 1 Case 1 aged 5. Referred at the age of 4 with speech problems from a developmental paediatrician. Hypotonia, undescended testes, mild intellectual impairment, and hypernasal speech. Height 10th centile. Note myopathic facies, almond shaped palpebral fissures, deficient nasal alae, long narrow nose and prominent nasal bridge, and apparent micrognathia. 


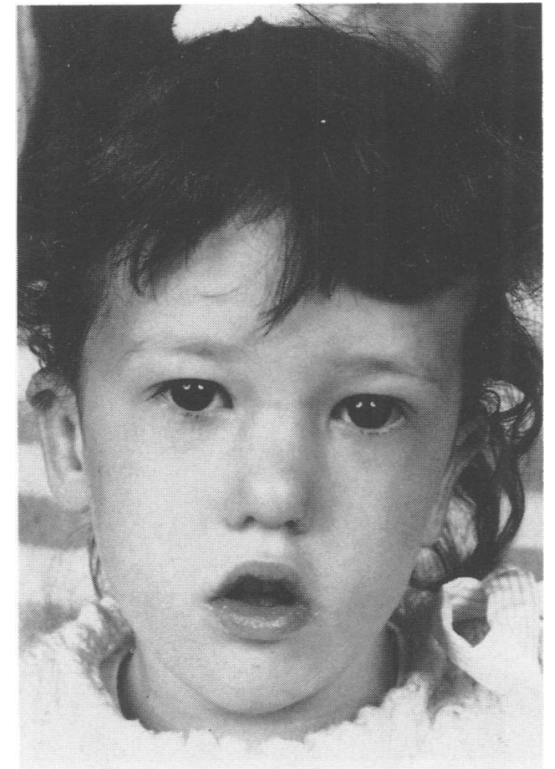

Figure 2 Case 2 aged 4. Cleft of the posterior palate noted at birth and repaired at 9 months. Velopharyngeal insufficiency noted with speech. Hypotonia and learning difficulties. Height 3rd centile. Note myopathic facies, almond shaped palpebral fissures, underdeveloped ears, deficient nasal alae, long narrow nose, prominent nasal bridge, and apparent maxillary and mandibular hypoplasia.

(range 9 months to 30 years). Ethnic distribution reflected the general population, with the majority being white Caucasians with origins from the United Kingdom and Europe. Two were from Chinese, three Italian, two Yugoslav, one Greek, and one Lebanese backgrounds.

Each patient was evaluated dysmorphologically and genetically by AHL with a three generation family history, a standard questionnaire concerning medications and other influences during pregnancy, and examination of other family members if appropriate. All patients with hypernasal speech had cinefluoroscopy to evaluate palatal length and movement. The patients were evaluated over a period of 10 years, 1980 to 1990 .

Speech therapy assessments were performed when possible before and after pharyngoplasty. Assessment of the response was made six months after surgery and graded as excellent (normal speech, normal tone, no nasal airway escape, normal articulation), good (inconsistent nasal airway escape, mild tone discrepancy), fair (no considerable improvement in tone but improved intelligibility/articulation), poor (only marginal improvement in tone, articulation/intelligibility), and no response (no change from preoperative status).

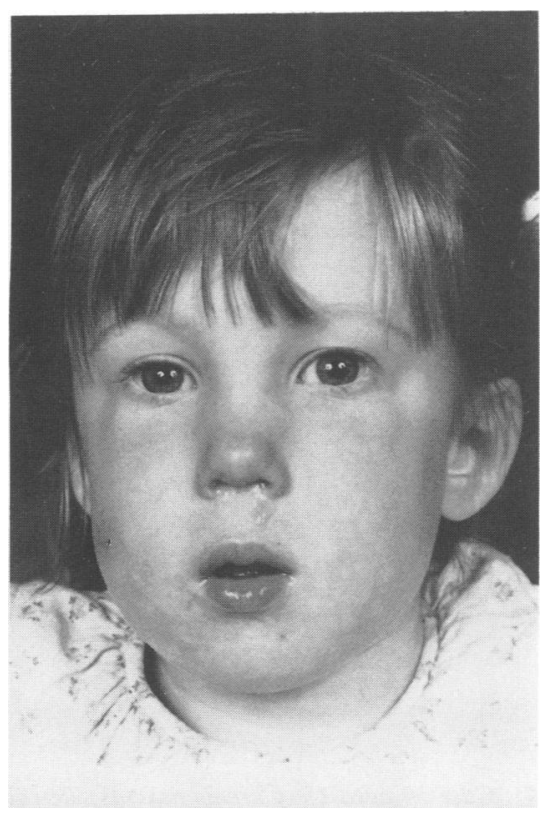

Figure 3 Case 3 aged $3 \frac{1}{2}$. Referred from a neurologist at the age of 9 months for dysmorphic and genetic assessment. Hypotonia, nasal regurgitation of feeds, submucous cleft palate, and umbilical hernia. No cardiac anomaly. Height 3rd centile. Note subtle facial dysmorphic features.

Velopharyngeal insufficiency was confirmed at the age of 3 when hypernasal speech was obvious. Learning difficulties.

\section{Dysmorphology}

CLEFT PALATE (TABLES 1 AND 2)

Seven patients had overt and 15 submucous clefts of the palate. Two children had associated cleft of the lip with overt cleft of the palate.

\section{CONGENITAL HEART DISEASE (TABLES 2 AND 3 )}

Sixteen patients had congenital heart disease, the most common lesions being tetralogy of Fallot and ventricular septal defect. Unusual defects such as various hypoplasias of pulmonary arteries, hemitruncus, and interrupted aortic arch were seen. Only one child had a right sided aortic arch, the case with double aortic arch and vascular ring (case 28).

\section{ASSOCIATED ANOMALIES (TABLE 4)}

Nineteen patients had anomalies other than clefting and congenital heart disease.

\section{TYPICAL FACIES}

All patients had the typical face consisting of a long nose with a broad, squared root and deficient alae, narrow alveolar base, flattened malar eminences and 


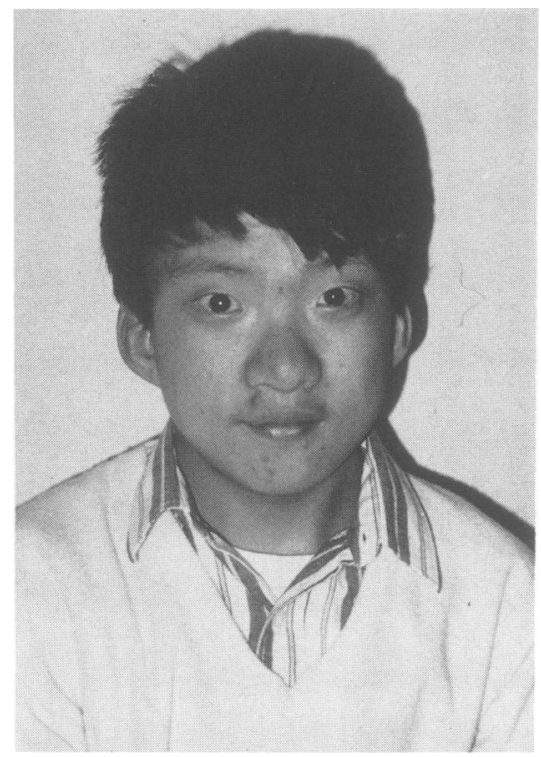

Figure 4 Case 10 aged 15. Chinese parents. Tetralogy of Fallot corrected at the age of 3. Velopharyngeal insufficiency corrected by palatoplasty aged 5. Learning problems at school needing remedial classes. Normal height. Hypotonia in first years. Now clumsy and poor at sports. Subclinical $T$ cell subset deficiency and hypocalcaemia detected at the age of 15 . Note bulbous nasal tip often noted in mature cases.

small mandible, myopathic facies often associated with almond shaped palpebral fissures, and minor malformations and prominence of the auricles. The mouth was often small and open resulting in a misdiagnosis of 'adenoid' facies. A notable feature in some children was small nasal openings. Older patients had an appearance of a broad bulbar tip to the nose.

\section{OTHER FEATURES (TABLE 2)}

Other features included hypotonia, particularly in the first years of life, learning difficulties, mild to severe retardation, small stature, and tapering fingers. Ureteric reflux, hypocalcaemia, $T$ cell anomalies, and abdominal hernias were seen.

\section{VELOPHARYNGEAL INCOMPETENCE}

All but one child had velopharyngeal incompetence as assessed by a speech pathologist or videofluoroscopy or both. The exception was one of sibs (case 24) who was recognised because of the presentation of his sib with velopharyngeal incompetence. Hypernasal speech coupled with delayed expressive speech, learning difficulties, retardation, small stature, and secondary psychological overlay caused by

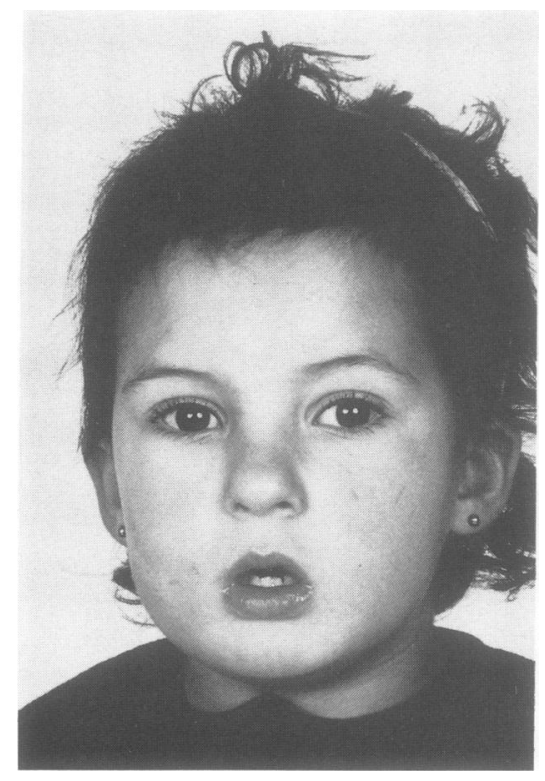

Figure 5 Case 27 aged 5. Submucous cleft of the palate recognised and repaired at the age of 3. Developmental delay and hypotonia. Height between the 3rd and 10th centiles. Velopharyngeal incompetence confirmed at the age of 4. Note deficient nasal alae, small open mouth, almond shaped palpebral fissures, underdeveloped ears.

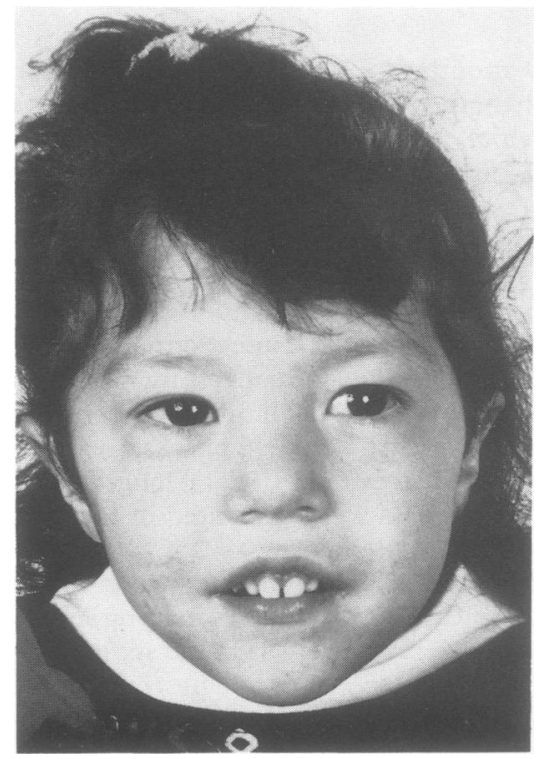

Figure 6 Case 30 aged 3. Diagnosed at 3 months by paediatrician. Cleft soft palate repaired at 9 months. Perimembranous ventricular septal defect, bilateral coloboma, hypocalcaemic fit at 3 weeks.

?Hypoparathyroidism, small stature (height 3 rd centile), and developmental delay. 


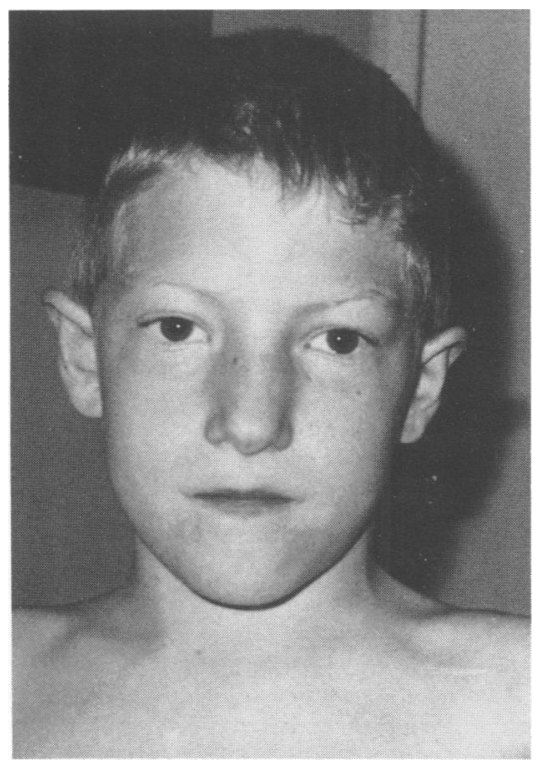

Figure 7 Case 32 aged 8. Interrupted aortic arch, ventricular septal defect, atrial septal defect.

Hypocalcaemic fit aged 3 months. Nasal regurgitation of feeds in first year of life. Submucous cleft of palate diagnosed at the age of 4. Hypotonia. Aged 8, calcium normal, $T$ cell studies borderline abnormal result. Normal intelligence. Diagnosis of VCFS aged 8 and definitive treatment of hypernasal speech offered after 4 years of speech therapy. Note almond shaped palpebral fissures, long narrow nose, deficient nasal alae, apparent maxillary and mandibular hypoplasia, and prominent deficient ears.

decreased intelligibility combined to make the speech very poor in many children. A history of nasal regurgitation of feeds in the first year of life was very prominent in the children who did not have an overt cleft; at least 15 gave such a history. It was often misdiagnosed as oesophageal reflux. This settled after the first year of life in all cases. Two children had started sign language as a method of communication. Both had a good response to pharyngoplasty. The children and their families were frustrated by the lack of intelligibility and this often resulted in social withdrawal. The patients were uniformally unresponsive to speech therapy, often continuing for some years with no success.

\section{RESPONSE TO PHARYNGOPLASTY}

Twenty-four had a detailed speech therapy assessment at least six months after pharyngoplasty. Of these, 15 had an excellent response, four had a good response, four a fair response, and one a poor response. Improvement occurred up to four years after operation. No postoperative obstructive sleep apnoea was seen. Many children have not been

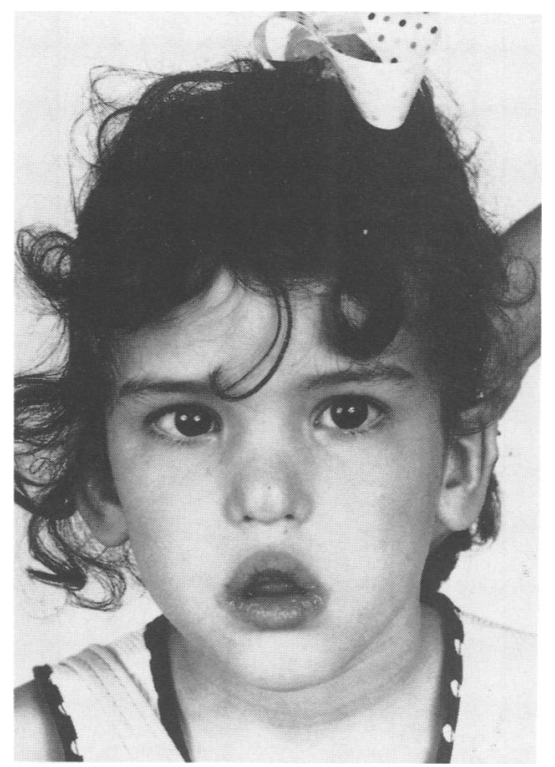

Figure 8 Case 38 aged $4 \frac{1}{2}$. Referred from speech therapist at the age of 4. Hypernasal speech. Submucous cleft palate. Velopharyngeal insufficiency. Note myopathic facies, almond shaped palpebral fissures, deficient nasal alae, maxillary and mandibular hypoplasia. Normal height and development. Very small nasal and external auditory openings.

assessed for this long, so that improvement could still occur. The oldest patient operated on was $15 \cdot 2$ years when he had the procedure and had a poor response. One who was operated on at 14.4 years had a fair response. A strong clinical impression was that operation in infancy produced a quicker and better response. In addition, a marked improvement in confidence, vocabulary, and general ability was noted in many children who appeared to be socially withdrawn because of their lack of intelligibility. Two children who were using sign language before operation had a good response, with rejection of

Table 1 Major features $(\mathrm{n}=38)$.

\begin{tabular}{lrr}
\hline & No & $\%$ \\
\hline Overt cleft palate & 7 & 18 \\
Associated with cleft lip & 2 & 5 \\
Submucous cleft palate & 15 & 39 \\
Congenital heart disease & 16 & 42 \\
Other defects & 21 & 55 \\
Hypotonia & 29 & 76 \\
Learning deficiencies/retardation & 31 & 82 \\
Small stature ( $\leqslant$ 3rd centile) & 24 & 63 \\
Dysmorphic face & 38 & 100 \\
Pharyngoplasty & 34 & 89 \\
\hline
\end{tabular}


Table 3 Congenital heart disease $(n=16)$.

\begin{tabular}{|c|c|c|}
\hline & No & Case No \\
\hline $\begin{array}{l}\text { Pulmonary atresia with ventricular } \\
\text { septal defect, both left sided aortic } \\
\text { arch } \\
\text { Ventricular septal defect only } \\
\text { Ventricular septal defect and } \\
\text { hyoplastic pulmonary arteries } \\
\text { Tetralogy of Fallot (one with } \\
\text { hemitruncus, all left sided aortic } \\
\text { arch) } \\
\text { Vascular ring/double aortic arch } \\
\text { Pulmonary stenosis, atrial septal } \\
\text { defect } \\
\text { Interrupted aortic arch (associated } \\
\text { with VSD, ASD 1) }\end{array}$ & $\begin{array}{l}3 \\
1 \\
1 \\
2\end{array}$ & $\begin{array}{l}19,34 \\
2,14,17,18,26,30 \\
9\end{array}$ \\
\hline
\end{tabular}

Table 4 Associated anomalies.

\begin{tabular}{lclr}
\hline & No & \multicolumn{1}{c}{ Case No } & $\%$ \\
\hline Ureteric reflux & 4 & $7,19,21,23$ & 10 \\
Umbilical hernia & 2 & 22,25 & 5 \\
Inguinal hernia & 3 & $22,33,35$ & 8 \\
Undescended testes & 3 & $1,7,33$ & 8 \\
Talipes & 4 & $14,20,26,33$ & 10 \\
Hypocalcaemia 1st year & 5 & $5,30,32,33,34$ & 13 \\
Proven hypoparathyroidism & 3 & $5,33,34$ & 8 \\
Proven T cell deficiency & 2 & 10,33 & 5 \\
Vertical talus & 1 & 34 & 3 \\
Hypospadias & 1 & 6 & 3 \\
Sprengel's shoulder & 1 & 4 & 3 \\
Hypermetropia & 1 & 38 & 3 \\
Myopia & 1 & 16 & 3 \\
Scoliosis & 1 & 26 & 3 \\
Laryngeal web & 1 & 29 & 3 \\
Bilateral coloboma of iris & 1 & 30 & 3 \\
Bilateral preauricular sinus & 1 & 4 & \\
\hline
\end{tabular}

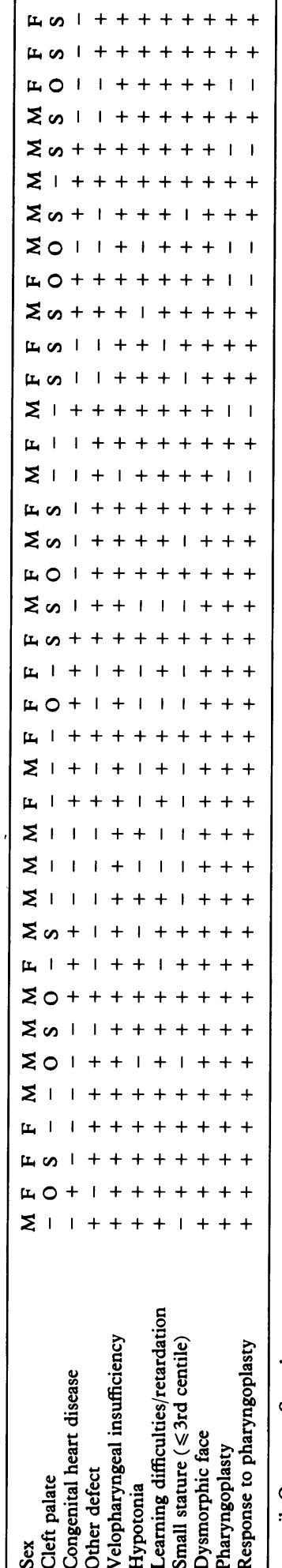


retardation, hypotonia, myopathic facies, small stature, and typical facies. He did not have velopharyngeal incompetence. The second familial case was a mild to moderately retarded 30 year old man with minimal hypernasal speech, typical facies, and congenital heart disease, whose twin brother and mother had died of congenital heart disease (cause unknown). These two latter persons were not examined and there are no photographs available. This familial case is therefore provisional.

\section{PREVIOUS ASSESSMENTS AND TREATMENT}

Eight patients were assessed by developmental paediatricians, three by geneticists, and four by paediatric neurologists for developmental, speech, and dysmorphic features during infancy and after speech had started without a specific dysmorphological or speech diagnosis. Treatment of the hypernasal speech was delayed for periods of one to seven years. Most had been treated during this time by speech therapists on a medical referral with no response. Most had been seen by a paediatrician, or a cardiologist, if a cardiac lesion was present, a general practitioner, or ENT surgeon in the first years of life and before and after speech had started. Two children had had adenoidectomy because of the confusion between hypernasal and hyponasal speech and the myopathic facies, exacerbating the hypernasal speech. Two children had had extensive therapy for hypotonic cerebral palsy. Three children had had a provisional diagnosis of VCFS made before speech started, one by a paediatrician at 3 months and two by the dysmorphologist member of the cleft palate team at 9 months and 2 years.

\section{REFERRALS}

Other than referrals by the clinic team, nine children were referred by speech therapists, eight by general paediatricians, two by developmental paediatricians, four by ENT surgeons, two by general practitioners, one by a general paediatrician, and one by a school. Tẉo referred by developmental paediatricians and one by a general paediatrician had the diagnosis of VCFS already made. Others were referred to clinic team members because of palatal, speech, or dysmorphological problems. Treatment of an overt cleft at the cleft palate clinic facilitated the diagnosis. In the latter part of the study period, clinical presentations by clinic members caused confident referrals from speech therapists and developmental paediatricians.

\section{Discussion}

Although the velocardiofacial syndrome (VCFS) has now been delineated for over a decade ${ }^{1}$ there is still a relative paucity of reports from centres not associated with the original reporting institution. Shprintzen et $a^{12}$ have now reported 60 cases from New York City, Meinecke et $a^{6}{ }^{6}$ eight cases from Germany, Mackenzie-Stepner et $a l^{13}$ three from Canada, Stevens et $a l^{4}$ two cases from Salt Lake City, and Wraith et $a l^{30}$ one case from Great Britain. In Shprintzen's clinic at the Montefiore Medical Centre, New York City, $8.1 \%$ of children with palatal clefts have VCFS. ${ }^{8}$ In our clinic, VCFS accounts for $5 \%$ of the palatal cleft population. The number of children has justified the establishment of a VCFS parent support group over the last 12 months. The ethnic background of our population is generally the same as North America, with a predominant white Caucasian population from the United Kingdom and Europe. Clearly the syndrome is either not recognised or not being reported. Our experience supports the former contention. The craniofacial and cleft palate clinic where this study was undertaken serves a statewide population of 5 million with 80000 births per year seeing approximately $90 \%$ of craniofacial and clefting disorders. VCFS appears to be very variable with incomplete forms being recognised. Twenty-two $(57 \%)$ have either overt or submucous clefts in contradistinction to the original reports of Shprintzen et al ${ }^{3}$ which cite up to $100 \%$ as having cleft palate. This may be associated with the definition of submucous cleft at operation, which has generally been conservative in our clinic. The fact that cardiac disease was uncommon, the presence of hypotonia and learning problems inconstant, and a family history rare may have hindered the diagnosis. Shprintzen et al ${ }^{1}$ described the syndrome in 1978, three years before the first case was recognised at our clinic.

Diagnostic evaluation included exclusion of other chromosomal, teratogenic, and genetic aetiologies. Differential diagnosis includes trichorhinophalangeal syndrome, ${ }^{14}$ Stickler syndrome, ${ }^{15}$ the fetal alcohol syndrome, ${ }^{16}$ FG syndrome,${ }^{17}$ and myotonic dystrophy. ${ }^{18}$ The face has many features of a hypotonic or myopathic face and shares characteristics with other syndromes with hypotonia, such as the almond shaped palpebral fissures in Prader-Willi syndrome, the FG syndrome, ${ }^{17}$ and even congenital facial paralysis as seen in Moebius syndrome. ${ }^{19}$ No patient was seen with the Pierre-Robin syndrome though this has been noted by Shprintzen et al. ${ }^{3}$

Shprintzen et $a l^{3}$ noted four unaffected mothers who had been given progestational agents during the early first trimester and one mother was an operating room nurse who had been exposed to anaesthetic gases during pregnancy. No cases in this series have reported a mother exposed to progestogens or anaesthetic gases during pregnancy.

Five cases of hypocalcaemia were seen and this has been reported before. ${ }^{3412}$ Three had proven 
hypoparathyroidism and, of these, two had proven $\mathrm{T}$ cell dysfunction. Certainly the Di George sequence is in the differential diagnosis of this syndrome; in particular the association of complex cardiac defects of neural crest origin with some of the dysmorphic and developmental associations may mean that many reported cases of Di George sequence may actually have the VCF syndrome. Stevens $e t a l^{4}$ reported two families with Di George sequence and VCFS. Shimizu et $\mathrm{al}^{20}$ and Radford et $a l^{21}$ studied children with conotruncal congenital heart disease and a dysmorphic face and found $T$ cell abnormalities in the majority of those tested. Goldberg et $a l^{5}$ and Shprintzen et al ${ }^{12}$ reported, among 60 patients with the VCFS, a high incidence of infections, diminished lymphoid tissue, transient hypocalcaemia in the first year of life, and $T$ cell abnormalities. Williams et $a l^{10}$ subsequently reported a higher incidence of adenoidal hypoplasia in VCFS, which would further accentuate velopharyngeal insufficiency. The association of dysmorphic facies, palatal clefts, conotruncal cardiac anomalies, and other anomalies suggestive of VCFS have been reported by Shimizu et al, ${ }^{20}$ Rohn et al, ${ }^{22}$ Kepper et $a l{ }^{23}$ and Radford. ${ }^{24}$ Wyse $e t ~ a l^{25}$ noted the association of conotruncal congenital heart disease with clefts of the lip and palate. Kepper $e t a l^{23}$ and Rohn et $a l^{22}$ described autosomal dominant transmission and Shimizu et $a l^{20}$ recognised an affected parent in six of 36 patients with the conotruncal anomaly face syndrome, which they recognised as probably analogous to VCFS.

Recent animal experimental work involving ablation of premigratory cranial neural crest has shown that conotruncal ${ }^{2627}$ and thymic abnormalities ${ }^{28}$ may result. The cranial neural crest that participates directly in heart development has been mapped using quail to chick neural crest transfer in vivo. ${ }^{2627}$ The region called the cardiac neural crest extends from the level of the midotic placode to the caudal limit of somite 3 and migrates into pharyngeal arches 3,4 , and 6 . These contribute to the development of the aortic arch and outflow tracts where they form the aorticopulmonary septum and populate the truncal folds. The thymus develops from pharyngeal arches 3 and 4 and ablation of the premigratory neural crest has been shown to result in reduction or absence of the thymus in the experimental animal. ${ }^{28}$ Abnormalities of neural crest migration are also involved in the development of the face and palate, including the muscles of the face. ${ }^{29} \mathrm{It}$ is clear that there is an embryological basis for the VCFS. Stevens $e t \mathrm{al}^{4}$ reported the association of Di George sequence and VCFS in two families, indicating dominant inheritance, and presented data to indicate that the familial cases of Di George syndrome reported by Kepper et $a l^{23}$ and Rohn et $a l^{22}$ may represent VCFS transmitted as a dominant trait.
This tends to support dominant inheritance, at least when overt or subtle $T$ cell changes are present.

The type of congenital heart disease in our cases was consistent with a conotruncal classification: vascular ring, interrupted aortic arch, hypoplastic pulmonary arteries, hemitruncus, tetralogy of Fallot, and ventricular septal defect. One child had a muscular ventricular septal defect, the others were membranous or supracrystal. Young et al, ${ }^{9}$ from Shprintzen's clinic, reported 23 cardiac anomalies in their first 27 cases, including ventricular septal defect, tetralogy of Fallot, and right sided aortic arch. No case with a cardiac lesion had a right sided aortic arch except the child with vascular ring (case 16). Truncus arteriosus was seen in case 1 of Stevens $e t$ $a l^{4}$ and the illustrations in the articles of Radford ${ }^{24}$ and Shimizu et $a l^{20}$ of facial anomalies with conotruncal congenital heart disease are very suggestive of VCFS. The survival of children with severe conotruncal anomalies has improved dramatically in the last 10 years owing to advances in cardiac surgery. The paucity of cases of truncus arteriosus and interrupted aortic arch in the original series of Young et $a l^{9}$ may be because their cases were reported at least 10 years ago, before good survival of this group was recorded.

The family histories in cases 23 and 24 (sibs) and case 26 (twin brother and mother) are of interest. Unfortunately, no further information is available on the facial appearance or type of cardiac lesions in the family of case 26. Dominant inheritance is likely. In the family with sib recurrence (cases 23 and 24), case 24 is an incomplete case only ascertained because of the typical features in his sister. The parents are normal and there are no other affected family members. This could either indicate germinal mosaicism in a normal parent or recessive inheritance. The twin cousins of this case have cleft palate and are reported to be of normal height and intelligence and without dysmorphic features or other anomalies. Several other familial cases have been reported indicating dominant inheritance with transmission from parent to child, including male to male transmission by Williams et al, ${ }^{7}$ four families by Shprintzen $e t a l,{ }^{3}$ two families by Meinecke $e t ~ a l,{ }^{6}$ six by Shimizu et al, ${ }^{20}$ and two by Stevens et al. ${ }^{4}$ Wraith et al ${ }^{30}$ reported a mother with tetralogy of Fallot and velocardiofacial syndrome having offspring with tetralogy of Fallot and holoprosencephaly. This case must be considered as doubtful as the mother's features, especially the absence or presence of velopharyngeal incompetence, are not well documented. No chromosomal anomalies have been shown to be associated. No common environmental agent or teratogen has been noted. It is likely that there is heterogeneity in the causes of VCFS and non-genetic phenocopies to account for at least some 
of the other patients, and counselling should take this into account.

The cause of the severely hypernasal speech is probably multifactorial, including pharyngeal hypotonia readily seen on videofluoroscopy, increased pharyngeal width associated with platybasia, increased distance between the pterygoid plates, ${ }^{9}$ and adenoidal hypoplasia. ${ }^{10} \mathrm{~A}$ standard repair of an overt or submucous cleft was never adequate to prevent velopharyngeal insufficiency.

The study of Arvystas and Shprintzen ${ }^{31}$ reported cephalometric evidence of platybasia indicating that the facial features of retrognathia, malar deficiency, and prominence of the nasal root may be not primary but secondary to this feature. They wondered whether landmarks at the cranial base could be altered by abnormally weak muscular forces in the nasopharynx, and posed a hypothesis that the cranial and facial findings of the syndrome could merely be secondary to neurogenic muscular weakness of a pre- and postnatal time course. Almond shaped eyes are seen in other muscular hypotonic syndromes affecting the face, such as the Prader-Willi and FG syndromes and myotonic dystrophy. The association of inguinal and umbilical hernias, and perhaps even vesicoureteric reflux, may be further indication for a secondary effect of muscular deficiency. Talipes was seen in four patients, but none required operative reduction. This may result from intrauterine deformation secondary to hypotonia, which is self-corrective after birth. Hypotonia of the mandible and tongue could cause retrognathia and prolapse of the tongue into the posterior pharynx, obstructing palate closure and resulting in a $U$ shaped posterior cleft palate. Hypotonia of the palatopharyngeal structures in utero may give rise to submucous clefts of the palate and incomplete insertion of muscular fibres.

Studies of the cleft palate population have shown that children with clefts tend to be smaller than those without, ${ }^{32}$ suggesting nutritional deprivation as infants. These studies all assume that such a population was homogeneous when it has now been shown to be highly heterogeneous by studies such as that by Shprintzen et al. ${ }^{8}$ However, it is now likely that these children, in fact, have syndromes such as the velocardiofacial syndrome.

The relative commonness of this syndrome in the population of children with clefts and speech problems seems at variance with an apparent failure to diagnose this dysmorphological syndrome. Underdiagnosis by therapists and paediatric subspecialists often resulted in prolonged and fruitless speech therapy and the inadvertent withholding of a quite effective treatment of the hypernasal speech by pharyngeal surgery. There was no response to speech therapy in any child until after pharyngoplasty. Although the cause and definitive treatment of VCFS may elude us in the majority of cases, surgery, speech therapy, developmental treatment, and genetic counselling provide a good quality of life for these children and their families. Diagnosis should be considered in any child with a conotruncal cardiac anomaly, particularly if associated with clefting, Di George sequence, or hypoparathyroidism. Nasal regurgitation of feeds in the first year of life, poor growth, hypotonia, and later developmental problems, as well as facial dysmorphism, should give a high index of suspicion of a diagnosis of VCFS. The children in whom the diagnosis is suspected should be followed carefully until speech starts as it is then that a functional palatal problem may first be evident, even if a cleft palate has been repaired previously. Expressive speech delay was common and tended to delay the diagnosis. Facial dysmorphism may also not be obvious in the first years of life. There are subtle changes in the facial appearance with age, with the teenage and adult patients developing a bulbar and broad tip to the nose. Other reports of adults have a similar bulbar nasal tip, such as in case 7 of Meinecke et al. ${ }^{6}$ The absence of cardiac disease should not deter the clinician from a diagnosis of VCFS. Only $42 \%$ of our cases had congenital heart disease. Differences in this series from those previously published ${ }^{1312}$ included absence of the Pierre-Robin sequence and the association of cleft lip in two cases and ureteric reflux in four cases. All those with ureteric reflux required antireflux surgery, though there was no associated renal malformation or damage. We did see cases of laryngeal web, scoliosis, abdominal hernias, and undescended testes which have all been described before. Genetic counselling should be approached on a patient by patient basis and should include examination of other family members and studies of $T$ cell function. Abnormalities in $T$ cell subsets and hypoparathyroidism may indicate a dominant inheritance pattern, ${ }^{4}$ though this was not recognised in families of such children in this series. Many patients with the Di George sequence may have the VCFS. Confident counselling of dominant inheritance in every case would presuppose an exceptionally high spontaneous mutation rate, which is unlikely. The known association of Di George sequence with chromosomal anomalies, such as deletion of the long arm of chromosome $22,3^{33-35}$ and teratogenic insults, such as ethanol ${ }^{36}$ and retinoic acid ${ }^{37-39}$ may mean that monogenic VCFS probably accounts for only a proportion of the total cases. However, at present no chromosomal or teratogenic association with VCFS has been described, although the overlap with the fetal alcohol syndrome has been noted before. ${ }^{29}$

We wish to thank Miss Michelle Giaquinto and Anne Lyon for secretarial assistance, Lyndal Le Bas 
for case finding, our colleagues for referring their cases, and the families and children with VCFS for their cooperation.

1 Shprintzen RJ, Goldberg RB, Lewin ML, et al. A new syndrome involving cleft palate, cardiac anomalies, typical facies and learning disabilities. Velo-cardio-facial syndrome. Cleft Palate $f$ 1978;15:56-62.

2 Strong WB. Familial syndrome of right-sided aortic arch, mental deficiency and facial dysmorphism. $f$ Pediatr 1968;73:882-8.

3 Shprintzen RJ, Goldberg RB, Young D, Walford L. The velocardio-facial syndrome: a clinical and genetic analysis. Pediatrics 1981;67:167-72.

4 Stevens CA, Carey JC, Shigeoka AO. Di George anomaly and velocardiofacial syndrome. Pediatrics 1990;85:526-30.

5 Goldberg $R$, Marion $R$, Borderon $M$. Phenotypic overlap between velo-cardio-facial syndrome and $\mathrm{Di}$ George sequence. Am F Hum Genet 1985;37:54A.

6 Meinecke A, Beeomer FA, Schinzel A, Kushnick T. The velocardio-facial (Shprintzen) syndrome. Eur $\mathcal{f}$ Pediatr 1986;145:539-44.

7 Williams MA, Shprintzen RJ, Goldberg RB. Male to male transmission of the velo-cardio-facial syndrome: a case report and review of 60 cases. I Craniofac Genet Dev Biol 1985;5:175-80.

8 Shprintzen RJ, Siegel-Sadewitz VL, Amato J, Goldberg RB. Anomalies associated with cleft lip, cleft palate or both. $A m \mathcal{F}$ Med Genet 1985;20:585-95.

9 Young D, Shprintzen RJ, Goldberg RB. Cardiac malformations in the velocardiofacial syndrome. Am $\mathcal{F}$ Cardiol 1980;46:6437.

10 Williams MA, Shprintzen RJ, Rakoff SJ. Adenoid hypoplasia in the velo-cardio-facial syndrome. $\mathcal{F}$ Craniofac Genet Dev Biol 1987;7:23-6.

11 Golding-Kushner KJ, Weller G, Shprintzen RJ. Velo-cardiofacial syndrome: language and psychological profiles. $f \mathrm{Cra}-$ niofac Genet 1985;5:259-66.

12 Shprintzen RJ, Wang F, Goldberg $R$. The expanded velocardio-facial syndrome: additional features of the most common clefting syndrome. Am $\mathcal{F}$ Hum Genet 1985;37:37A.

13 Mackenzie-Stepner K, Witzel MA, Stringer DA, Lindsay WK, Munro IR, Hughes H. Abnormal carotid arteries in the velocardiofacial syndrome: report of three cases. Plast Reconstr Surg 1987;80:347-51.

14 Langer LO, Krassikoff N, Laxova R, et al. The tricho-rhinophalangeal syndrome with exostoses. Four additional patients and a review of the literature. Am $\mathcal{F}$ Med Genet 1984;19:81111 .

15 Temple IK. Stickler's syndrome. 7 Med Genet 1989;26:119-26.

16 Lipson AH, Webster WS, Walsh DA. The fetal alcohol syndrome: a great paediatric imitator. Med f Aust 1983;1:266-70.

17 Thompson E, Baraitser M. FG syndrome. f Med Genet 1987;24:139-43.

18 Harper PS. Myotonic dystrophy. Philadelphia: Saunders, 1979.

19 Lipson AH, Webster WS, Weaver DD. Moebius syndrome: aetiology, incidence of mental retardation, and genetics. $f$ Med Genet 1990;27:533-5.
20 Shimizu T, Takao A, Ando M, et al. Conotruncal anomaly face syndrome: its heterogeneity and association with thymus involution. In: Nora JJ, Takao A, eds. Congenital heart disease: causes and processes. Mount Kisco, NY: Futura, 1984:29-41.

21 Radford DJ, Perkins L, Lachman R, Thong YH. Spectrum of Di George syndrome in patients with truncus arteriosus: expanded Di George syndrome. Pediatr Cardiol 1988;9:95101.

22 Rohn RD, Leffell MS, Leadem P, et al. Familial third and fourth pharyngeal pouch syndrome with apparent autosomal dominant transmission. F Pediatr 1984;105:47-51.

23 Kepper LD, Fasules JW, Burks AW, et al. Confirmation of autosomal dominant transmission of the Di George malformation complex. F Pediatr 1988;113:506-8.

24 Radford DJ. Truncus arteriosus and facial dysmorphism. Aust Paediatr F 1985;21:131-3.

25 Wyse RKH, Mars M, Al-Mahdani S, Russell-Eggitt IM, Blake $\mathrm{KD}$. Congenital heart anomalies in patients with clefts of the lip and/or palate. Cleft Palate 7 1990;27:258-63.

26 Kirby ML. Role of extracardiac factors in heart development. Experimentia 1988;44:944-51.

27 Kirby ML, Bockman DE. Neural crest and normal development: a new perspective. Anat $\operatorname{Rec} 1984 ; 209: 1-6$.

28 Bockman DE, Kirby ML. Dependence of thymus development on derivatures of the neural crest. Science 1984;223:498-500.

29 Sulik KK, Cook CS, Webster WS. Teratogens and craniofacial malformations: relationships to cell death. Development 1988;103(suppl):213-32.

30 Wraith JE, Super M, Watson GH, Phillips M. Velo-cardiofacial syndrome presenting as holoprosencephaly. Clin Genet 1985;27:408-10.

31 Arvystas M, Shprintzen RM. Craniofacial morphology in the velo-cardio-facial syndrome. F Craniofac Genet Dev Biol 1984;4:39-45.

32 Duncan PA, Shapiro LR, Saley RL, Turet SE. Linear growth patterns in patients with cleft lip or palate or both. Am $\mathcal{F} D i s$ Child 1983;137:159-63.

33 Kelly RI, Zackai EH, Emanuel BS, et al. The association of Di George anomalies with partial monosomy of chromosome 22. 7 Pediatr 1982;101:197-200.

34 De La Chapelle A, Herva R, Koivisto M, et al. A deletion in chromosome 22 can cause Di George syndrome. Hum Genet 1981;57:253-6.

35 Greenberg F, Crowder WE, Paschale V, et al. Familial Di George syndrome and associated partial monosomy of chromosome 22. Hum Genet 1984;65:317-19.

36 Amman AJ, Wara DW, Cowan MJ, Barrett DJ, Stiehm ER. The Di George syndrome and fetal alcohol syndrome. $A m \mathcal{F}$ Dis Child 1982;136:906-8.

37 Thayer JM, Adams EA, Effman EL, Sulik KK. Critical period for 13 cis retinoic acid induced aortic arch malformations precedes initial formation of the 4th visceral arch vessel. Teratology 1987;35:32A.

38 Thorogood PV, Smith L, Nicol A, McGinty R, Garrod D. Effects of vitamin $A$ on the behaviour of migratory neural crest cells in vitro. $\mathcal{F}$ Cell Sci 1982;57:331-50.

39 Lammer EJ, Chen DT, Hoar RM, et al. Retinoic acid embryopathy. N Engl f Med 1985;313:837-41. 